\title{
Food from the Sea.
}

Being the Presidential Address delivered before the

Plymouth Institution, October 14th, 1915.

By

E. J. Allen, D.Sc., F.R.S., Director of the Plymouth Laboratory.

[Reprinted from the Transactions of the Plymouth Institution.]

. . Passing now to the special subject of my address to-night, I will ask your attention in the first place to some general aspects of our Sea Fisheries as a source of national food supply and to the general scientific investigations which have been undertaken in the hope that the yield of the harvest of the sea may be still further increased. In the second place a more detailed account will be attempted of some particular researches bearing upon these matters, which happen to have formed during the past few years the subject of my own special work. If in the course of my remarks you may seem to be asked to follow me in excessive detail into some of the more remote corners of the problems which arise, my excuse must be that, even at the risk of upsetting the balance of the picture as a whole, it is probably possible to speak to more purpose and with a better prospect of stimulating others to fresh efforts, by describing researches with which I have been personally concerned, than by a more general and better proportioned, but necessarily more superficial treatment of the whole subject.

As a direct consequence of our geographical position, our immediate proximity to large areas of shallow sea, our extended coast-line, with its many fine harbours and serviceable fishing coves, lying at distances not too remote from the large centres of population, and of our well-developed railway systems, the sea fisheries of Great Britain have become of much greater relative importance as a source of food supply than has been the case in almost any other country of the world. The statistics for the year 1913, the last complete year for which normal figures are available, show that $1 \frac{1}{4}$ million tons of fish were landed in England, Scotland and Ireland, having a value at the port of landing of some 15 million pounds. 
By way of comparison, and to give you some idea of the relative importance of the industry, similar figures for one or two other sources of our food supply may be of interest. In the same year 1913, $1 \frac{1}{2}$ million tons of wheat were grown in the United Kingdom, as against the $1 \frac{1}{4}$ million tons of fish landed, the wheat being valued somewhere about 13 million pounds, as against 15 million pounds for the fish. Imported wheat was $5 \frac{1}{4}$ million tons, valued at 44 million pounds. Imported beef was valued at 16 million pounds, imported mutton at 11 million.

It should be added, however, that one-third of the total value of the fish landed is attributable to herrings, which were salted and exported chiefly to Germany and Russia, the sum received for these fish being 5 million pounds.

It is interesting to compare the value of fish landed in the United Kingdom with that of fish landed in other European countries. Of the total value of sea-fish landed in Europe in 1910, 47 $\frac{1}{2}$ per cent (very nearly one-half) stands to the credit of British fisheries, other countries showing France, 19 per cent ; Norway, 10 per cent ; Germany, 7 per cent; Holland, 7 per cent ; Sweden, 3 per cent ; Denmark, 3 per cent; Belgium, 1 per cent; Russia, 1 per cent.

From these figures you will see what a preponderating part our islands take in the total yield of the fisheries.

Now the two pressing questions which present themselves, from the practical point of view, are: Do we at present make the best possible use of the harvest of the fishing grounds? And how can the yield of human food in the form of fish be increased?

As a matter of fact from year to year, for many years past, the total quantity and the total value of the fish landed in this country have both shown a steady and continuous increase. Even since the year 1890, when the industry of steam-trawling was already in full swing, the total landings have doubled both in quantity and in value. This.increase has been brought about entirely by increasing the number and the power of the fishing vessels and extending the areas over which they have worked. To-day the region worked by the steam-trawlers, which bring their fish in ice to the English market, extends northwards to the Barent's Sea, off the north coast of Russia-the so-called White Sea grounds-to Iceland and the Faroes, and southwards through the Bay of Biscay to the banks off the coast of Morocco, trawling being carried on to a depth of 200 fathoms or even more. Doubtless this process of increasing the power of fishing vessels and extending the area over which they fish will still continue. Trawlers have already made experimental voyages to the Banks of Newfoumdland, and halibut from the Pacific Coast of Canada has been sent in a frozen state to the London market. This kind of develop- 
ment of the fisheries may well be left to the energy and enterprise of the fishing industry. The only useful help which the scientific expert might give, would be in making preliminary explorations of more distant grounds. Govermment has, however, never thought it right to provide public funds for work of this character, and it is probably better to leave it to the trade and the practical fishermen.

The subject with which fishery science is called upon to deal is rather, whether the best possible use is being made of the resources of food which the sea is capable of yielding in those waters in which fishing is already extensively and exhaustively carried on. British researches have dealt chiefly with the North Sea, the Irish Sea, the English Channel and the waters around the Irish coast. Are the methods of fishing now employed in these areas unnecessarily wasteful of fish life or could the total anmual landings be made more valuable by a more rational regulation of the methods of capture? Are there other means, analogous to the cultivation of the land, which might be adopted to improve the yield of the fishing grounds and to what extent could such means be profitably employed?

It must be at once admitted that, except to a very limited extent, we are not at present in a position to give definite answers to these questions. We camnot assert with confidence that any attempted regulation of the fisheries upon a considerable scale has been followed by marked and definite improvement. In matters of cultivation also, excepting as regards some of the fisheries for shell-fish, such as oysters and mussels, we are unable to point with certainty to any success upon a large scale, when dealing with sea fish.

And the reasons for this comparative inability to obtain favourable practical results are not far to seek. In the first place, the sea is so vast and so powerful are its elemental forces, that control by human agency must always be immensely difficult. We should not forget, however, that the evidence is now almost conclusive that human agency has been powerful enough to exert a marked adverse influence upon many of the best and most productive fishing grounds, and if destruction can be wrought by man, it should not be beyond his power to do something to repair the damage he has caused.

In the second place, our knowledge of the many complex factors with which we have to deal is still very imperfect. It is, indeed, only very slowly approaching a point when proposals for practical measures can be made with any hope of foreseeing what the actual effect of those proposals would be. In this direction much further enquiry and study will be required. Notwithstanding all that has been done in the way of research during the last thirty or forty years the gaps in our knowledge 
on many of the most fundamental points are very great. Until more adequate means can be secured for carrying out actual experimental work at sea progress cannot possibly be rapid, and many of the problems cannot be studied in a satisfactory way.

Slowly, however, we are building up a true science of the fisheries. The direction and velocity of the currents, the differences in temperature and salinity of the water, and the variations in these factors from season to season and from year to year upon which the fluctuations in the abundance of fish must very largely depend, are being gradually worked out and understood. The effects of wind and weather and of the varying amount of sunshine falling on the water in different years are questions which are being studied. Then again, the natural history of the fishes themselves is the subject of much research; their habits and food, when and where they spawn, the characters of the larval fishes and when and where their younger stages are to be found, all fall under this head.

Many of the results of investigations on these lines have already from time to time been described and discussed at the meetings of our institution, and for that reason I will not to-night dwell upon them, important -indeed, essential-as they are for an adequate understanding of the problems which have been put forward. It is to a more general aspect of the matter that I would especially refer-the question of how the primary or fundamental food supply of the sea is built up. Suppose that during the late summer or autumn we capture in the waters of Plymouth Sound, a mackerel. The body of that mackerel represents some $S$ ounces of excellent human food. What is the ultimate source from which that food has been produced? If we examine the stomach of the mackerel, we shall probably find it filled with small fishes, chiefly sprats and quite young herrings, with perhaps a certain number of those small, shrimp-like creatures which are known as Copepods. The young herrings and sprats have themselves fed largely upon Copepods of a similar kind. We conclude, therefore, that the body of the mackerel has been formed either directly, or indirectly, through the young herrings and sprats, from the organic substance contained in the bodies of the shrimplike Copepods. Then if we carry the problem a stage further back and enquire how the bodies of the Copepods have been built up, we find with the aid of a microscope that their food consists in large measure of minute plants, chiefly belonging to the class of diatoms.

We have here a particular and perhaps exceptionally simple and straightforward example of the general principle, applicable equally to land and sea animals, that the organic substance which constitutes their: flesh is always derived either directly or indirectly from vegetable life. 
The amount of animal life, therefore, which a given area of sea or land can support, depends upon the amount of plant life on which the animal life can feed.

When we push the enquiry further back we find, as you know, that the bulk of the plant substance consists, in addition to water, of compounds of the element carbon, which are known under the general name of organic compounds. This carbon is derived entirely from the carbonic acid gas present in the air or dissolved in the water, the gas being split up and the carbon assimilated by the plant in the presence of sunlight. The source of the energy by means of which all organic matter is built up is the light of the sun, whilst the great mass of the solid substance contained in the bodies of both animals and plants is derived ultimately from carbonic acid gas, obtained in the case of land plants from the air, in the case of sea plants from gas dissolved in the water. In addition to carbon and water the plant requires a number of other substances, chiefly inorganic salts, but the quantities of these which are necessary are comparatively small. In the case of land plants these salts are obtained from the soil, in the case of sea plants from the water in which they are dissolved.

It may be interesting here to compare the yield of organic substance derived from a given area of sea or fresh water with that from a similar area of land, to compare the harvest of the sea with the harvest of the land.

It has been calculated by Brandt, from the catches of fishermen in an enclosed harbour, that the anmual yield was $89 \mathrm{lbs}$. of fish per acre. In Continental carp ponds, where the culture has been carefully carried on, $95 \mathrm{lbs}$. of fish per acre per year have been obtained.

Making a similar calculation for the North Sea from the statistics of fish landed, we get, as we should expect, a much lower annual yield, namely, $15 \mathrm{lbs}$. of fish per acre. The average value of this is only $1 \mathrm{~s} .6 \mathrm{~d}$. per acre per year.

Beds of shellfish give a very much higher yield, but they of course in reality, owing to the tidal currents which pass over them, draw their food supply from a much greater area of water than that of the sea-floor to which they are attached. Johnstone finds for the uncultivated mussel beds of Morecambe Bay, on the Lancashire coast, a yearly production of 86 cwts. (or nearly $10,000 \mathrm{lbs}$.) per acre, valued at $£ 1416 \mathrm{~s}$. per acre.

For comparison with these figures here is one taken from agricultural statistics. Young bullocks fed on cultivated land give an average annual yield of $73 \mathrm{lbs}$. of beef per acre.

Putting the figures side by side we have first the mussels from More- 
cambe Bay, with a yearly production of $10,000 \mathrm{lbs}$. per acre; then in quite a different category :-

Fish from Carp Ponds . 95 lbs. per acre per year.

Fish from the enclosed Harbour . 89 lbs.

Beef from Young Bullocks . . 73 lbs.

Fish from the North Sea $15 \mathrm{lbs}$.

It will be seen, therefore, that although the figures for the open sea are far below those for cultivated land, more restricted areas of water are capable of producing a considerably greater weight of crop. Especially the figures for the mussel beds seem to indicate that much larger returns from the sea might be possible, if sufficient knowledge of the complex conditions of marine life could be successfully obtained.

The possibilities of a still greater yield have recently been suggested by Prof. Benjamin Moore of Liverpool, from observations made in the Irish Sea. This author has calculated from measurements of the change in alkalinity of the water, that under the action of sunlight there is an annual production of two tons of dry organic matter per acre, which would be equivalent to at least ten tons of moist vegetable substance. This is a preliminary estimate to which it would be unwise to attribute too great exactitude at present, but it does seem to confirm the view that we are as yet a very long way indeed from making full use of the organic food substance which the seas around our coasts are capable of producing.

And this leads me to ask your attention in a little more detail, to the particular aspect of the conditions upon which marine life depends, to which my own researches have recently been directed.

The marine vegetation, which constitutes the fundamental food supply of the sea, may be divided into two principal groups. All round our shores we find attached to the sea-floor the green, red and brown seaweeds. These form a fringe in the shallow water around the coast, but do not extend to a greater depth than about 15 fathoms, owing to the fact that sufficient light to enable them to grow does not penetrate through the water below this depth. Many animals feed upon these seaweeds as they grow, and recent researches by Danish naturalists seem to show that when the weeds die and decay the organic fragments into which they break up constitute an important source of food for many other animals, which in their turn serve as food for fish.

Outside this coastal fringe, however, the plant life of the sea consists of minute organisms, microscopic in size, which float freely in the water, and live and grow in the upper layers from the surface to a depth of 100 or 200 fathoms, or even deeper. Amongst these microscopic plants 
one of the most important and prolific groups is that of the diatoms. These plants possess a delicate and often very elaborately constructed skeleton of silica, and contain a brown colouring matter, which like the green chlorophyl of land vegetation is able in the presence of sunlight to assimilate the carbon from carbonic acid gas.

It has formed an interesting subject of research to endeavour to ascertain as exactly as possible the conditions necessary for the growth of these diatoms, and to find out by means of experiments in the laboratory how the amount of growth may be increased. In order to carry out such experiments with exactitude and to obtain precise and definite results it is necessary to work with cultures of a diatom which are as nearly as possible pure, that is to say, cultures which contain no other living organisms excepting the single species of diatom upon which the experiments are being made. If two or more living organisms are present in the experimental cultures the results at once become complicated, since a second organism not only uses up the different constituents in the culture solution, but it also excretes waste products of its own, which become dissolved in the water and may affect either favourably or unfavourably the growth of the diatom which is being experimented upon.

The experiments had, therefore, to be conducted as nearly as it was possible under sterile conditions. The glass flasks in which the cultures were made, after being carefully cleaned, were baked in an oven, and all the culture solutions were boiled before being used.

The particular diatom upon which the experiments were made is one that is found in the Plankton, that is to say amongst the large number of microscopic organisms which float freely in the waters of the sea, and are drifted about at the mercy of wind and current. Such organisms are collected by dragging through the water a bag-shaped net, made of muslin or fine-meshed silk, which strains them out. This form of net is generally known as a tow-net. The organisms collect in a tin or bottle attached to the end of the net, and can be brought alive to the laboratory in a bottle of sea-water.

The species of diatom used in the experiments is called Thalassiosira gravida. Each diatom cell consists of two flat, cup-shaped valves, fitting one into the other and enclosing the protoplasmic substance of the cell. The whole cell of Thalassiosira looks something like a flat, shallow pillbox. A number of these cells are joined together by threads, which run from the middle of one cell to the middle of the next, so that long chains are formed. These chains of diatoms have much the appearance of a number of buttons strung on a thin wire, with a considerable interval between successive buttons. This chain formation is of some importance 
in the experiments, because the length of the chains which are formed gives a good indication of the healthiness of the culture.

In order to obtain a pure culture of a Plankton diatom two methods may be used. The first-which, however, does not give very satisfactory or certain results in practice-is to pick out under the microscope, by means of a very fine glass pipette, a single cell or short chain of the diatom and put it in a flask containing a suitable culture solution.

The second method, which is the one I have more often used, is as follows: A glass flask, containing about 2 litres (say, half a gallon) of suitable culture solution, the nature of which I shall describe presently, is brought to the boil in order to kill off any animals or plants which may be present in it, and then allowed to cool. We then take some seawater containing a mixture of Plankton animals and plants, which have been collected with a fine silk net in the way already described, and add just one or two drops of it to the flask containing the half-gallon of. cold culture solution. The flask is shaken up, and the living organisms, which were present in the two drops of sea-water, become evenly distributed through it. The water in the flask is then divided up, by pouring it into, say, forty or fifty tiny flasks, and these small flasks are put to stand in a north light and kept at an even temperature. After a week or ten days a brownish growth appears in many of the flasks; and if the experiment is successful, that is to say if our one or two drops of water containing the mixture of organisms has been sufficiently divided up, we shall find in perhaps two or three of our fifty small flasks a pure culture of one of the Plankton diatoms. A culture once obtained in this way can be kept as long as we wish, by continually inoculating new flasks of sterile culture solution, transplanting to one new flask after another as often as may be desired. I have kept cultures alive in this way for six or seven years.

Such cultures are, however, not quite perfect. They always contain in addition to the diatoms some bacteria, and these are very difficult to get rid of ; indeed I have never really succeeded in entirely eliminating them. They may be greatly reduced by a process of differential poisoning. By adding to a series of culture flasks gradually increasing doses of chlorine gas, it is possible to hit off a strength of the poison which will kill most of the bacteria without killing the diatoms. In this way a culture of the diatom Thalassiosira was obtained in which there remained only one kind of micro-organism, or at least only one kind that could be detected in the ordinary way by growth on agar-agar plates. The experiments to be described were made chiefly with this culture. Its growth was very rapid and healthy under favourable conditions, and very long chains of diatoms were formed. 
Previous work dealing with the culture of diatoms had been done mainly by the French bacteriologist Miquel. Miquel himself investigated principally fresh-water diatoms, but he showed that the methods he employed could be used also for marine forms, his experiments in this direction having been made chiefly with shore and bottom species. My own work, in which during the earlier stages I received much assistance from my colleague, Mr. E. W. Nelson, has dealt mostly with the floating or Plankton diatoms, which are much more delicate organisms to deal with than the fresh-water or marine bottom forms.

Miquel showed that fresh-water diatoms could be most successfully grown when to the water there was added a very small quantity of certain inorganic salts, together with a small proportion of soluble organic matter, prepared by making an infusion or maceration of straw, bran or some other vegetable substance.

The inorganic salts, which Miquel considered necessary, were the following :-

Magnesium sulphate
Sodium chloride
Sodium sulphate
Ammonium nitrate
Potassium nitrate
Sodium nitrate
Potassium bromide
Potassium iodide
Sodium phosphate
Calcium chloride
Ferric chloride

Of these salts the most important were found to be the nitrates, the phosphate and the iron salt, a result which agrees with what we know of the requirements of plant-life in general. These three substances, especially the nitrates and phosphate, are as is well known largely used by farmers as artificial manures.

In order to grow marine diatoms, Miquel added to sea-water the same salts which he had used for growing fresh-water diatoms. Our experiments have shown, however, that it is by no means necessary to add all these salts to sea-water in order to get good cultures. Quite as good results can be obtained by the addition only of Potassium nitrate, Sodium phosphate and Iron chloride, the two latter being made into solution with calcium chloride and hydrochloric acid, according to. a special method described by Miquel.

If sea-water which has been obtained near the coast is used as the 
basis for the culture medium it is not necessary to add an infusion of organic matter.

The actual quantities of inorganic salts added to the sea-water are really very small, those employed in our later experiments being in 100,000 parts of sea-water :-

$$
\begin{gathered}
40 \text { parts of Potassium nitrate. } \\
4 \text { " " Sodium phosphate. } \\
4 \text { " , Calcium chloride. } \\
2 \text { ", "Ferric chloride. }
\end{gathered}
$$

When the culture solution has been prepared it is first boiled in order to kill off any organisms it may contain, and a precipitate which forms is allowed to settle. The clear water is then poured off into small flasks, in which the experimental cultures are made, a second boiling being carried out before the flask is inoculated with the diatom culture. The diatoms grow best at a temperature of about $60^{\circ} \mathrm{l}$., in a good north light. They must not be exposed to direct sunlight, as in the small flasks used this is found to kill them.

The culture solution just described has sea-water for its basis. Now sea-water is a very complex solution containing both inorganic and organic substances, and although it is true that the relative proportions of the predominating salts are remarkably constant everywhere in the sea, there are present in it also, often in very minute quantities, many other important substances which are subject to considerable variation from place to place and from time to time. These varying substances are in many cases just those which are of special importance to the living plant. They occur often in such minute traces that it is practically impossible to measure accurately by means of chemical analysis the quantities in which they are present.

In order, therefore, to study the effect on the growth of the diatoms of very small quantities of various substances a different method of procedure was adopted. Instead of using natural sea-water as the basis for the culture solutions, an artificial sea-water was built up by dissolving in pure distilled water the purest chemicals that could be obtained. The distilled water was made specially pure by distilling it a second time in all-glass apparatus, so that it did not come in contact with any metal such as tin or copper. Further, when being distilled for the second time, the water was boiled with bichromate of potash and sulphuric acid in order to destroy as far as possible any volatile organic matter what it might contain. By taking the right proportions of the pure chemicals and dissolving them in this doubly distilled water an artificial 
sea-water was made having as nearly as possible the composition of natural sea-water. It was, of course, also possible to make up artificial sea-waters of different compositions, one or other of the constituent salts being increased or diminished in amount, or omitted altogether.

What we may call the normal artificial sea-water, that is, the one with a composition as nearly as possible that of natural sea-water, had the - following constitution :-

Sodium chloride

Potassium chloride

Calcium chloride .

Magnesium chloride

Magnesium sulphate

Sodium bicarbonate
$28 \cdot 13$ grams per litre.

$\begin{array}{lll}.77 & , & " \\ 1.2 & " & " \\ 2.55 & , & , \\ 3.5 & " & , \\ .11 & , & ,\end{array}$

To this there was added in some of the experiments a trace of Potassium iodide and Potassium bromide, but the results did not seem to be affected by this addition.

There is another substance which requires careful consideration when we are dealing with diatom cultures. The skeleton of a diatom is composed of Silica, so that to get a healthy growth that substance must be supplied. An Austrian botanist, Richter, has shown that when cultures are made in glass vessels, enough silica dissolves from the glass to supply the diatoms with all they require. In my experiments I found that the addition of silica in other forms to the culture solutions appeared to make no difference to the growth. We may therefore in what follows disregard the silica, remembering that all the needful supply of it could be obtained from the glass of the flasks in which the experiments were made.

Having made the artificial sea-water in the way described the essential constituents of Miquel's solutions-Potassium nitrate, Sodium phosphate and iron-were added. After boiling and cooling, the flasks containing the solution were inoculated by adding a small quantity of a culture of the diatom Thalassiosira, which was already growing in natural seawater. The flasks were then placed in a good light and the cultures given an opportunity to develop.

In the early experiments the results were very uncertain and difficult to understand. In most cases there was an entire failure of growth, but every now and then quite a good growth was obtained. It was noticed also that a good growth more frequently resulted when a flask which had failed was inoculated a second or a third time. It remained for a long time a puzzle why the cultures should generally fail but occasionally succeed, until it occurred to me that the quantity of natural sea- 
water transferred to the artificial sea-water when the latter was being inoculated was not always quite the same, and that when a culture was inoculated two or three times a much larger quantity of natural seawater was introduced than when it was inoculated only once. Was it the addition of this increased quantity of natural sea-water that enabled the diatoms to grow in the purely artificial solutions? Definite experiments were made to determine this point, and it soon appeared that the previous irregularity of the results could be accounted for in this way. It was found that if the inoculations were always made by adding only a very small quantity of the liquid from which the living culture was taken, say, by adding just one or two drops of culture to a flask containing 75 cubic centimetres of artificial sea-water, only a very slight growth, if any at all, took place. If, however, before the artificial water was inoculated in this way, and also before it was sterilized by boiling, as little as 1 part in 100 of natural sea-water was added to it, the diatoms grew well and excellent cultures were obtained. With 4 per cent of natural sea-water added to the purely artificial solution the cultures were quite as good as, if not better than the best that were got when natural sea-water was used entirely as the basis of the culture solution.

This result is somewhat remarkable because it seems to show the absolutely essential importance to the growth of the diatoms of an extraordinarily minute trace of some substance which exists in the natural sea-water. In the artificial water all the salts were included that occur in natural sea-water in any quantity above a mere trace-a trace so small that it is hardly capable of accurate measurement. Yet when this trace of substance is diluted down by adding 1 part of it to 100 parts of artificial sea-water, there is still enough of it introduced to make a vigorous and abundant growth possible where no growth at all was possible without it. This substance can hardly itself be regarded as a food substance. Its real action can only be conjectured, but we may think of it as a growth stimulant without the aid of which the plant is unable to build up its structure out of the real food substances.

In the course of further experiments it was shown that, provided this small quantity of natural sea-water were present, the composition of the artificial sea-water could be altered to an extraordinary extent without much if any effect being produced on the culture. In the first place the density of the artificial water could be changed within very wide limits without affecting the cultures appreciably. The solution might be diluted to one-half the normal strength or even below, or it might be concentrated so as to increase the density by as much as 50 per cent.

All the Potassium chloride might be omitted or the amount of Potas- 
sium chloride might be doubled. Similarly the Magnesium sulphate could be omitted or doubled without detriment. In the case of the Calcium chloride, also, the amount of permissible variation was very great, though not quite so great as with the Potassium chloride and Magnesium sulphate. These results were a little surprising, as it had generally been assumed that the Plankton diatoms were particularly sensitive to changes in the composition of the medium in which they live. It is clear, however, that provided all the essential substances are present, in some cases even excessively minute quantities being sufficient, the composition of the medium can be very greatly altered without affecting the organisms.

Incidentally, the facts which I have been describing would appear to have an important bearing upon all theoretical questions concerning the relation of the organism to its environment. If such a minute change in the environment as is involved in the addition of 1 per cent of natural sea-water to the artificial solutions can make all the difference between reproduction and no reproduction of the diatom, can we be said in the case of any organism whatever to have an adequate conception of what the effective environment really is ? Clearly we are very far indeed from appreciating or understanding how intricate and varied are the many factors upon which the life of even the simplest plant or animal depends.

But this is a digression. Let us return to the diatom cultures, and ask what is the chemical nature of the essential substance, a trace of which must be present in the artificial culture solution before the diatoms can flourish. Up to the present I have been unable to give any final or adequate answer to this question. Certain hints and suggestions have, however, been obtained which give us an indication of the lines upon which the answer to the question is to be sought. Some of the experiments which have given rise to these suggestions may be of interest to you.

To a flask containing some of the artificial sea-water, which had been treated with nitrate, phosphate and iron, a small fragment of the green seaweed Ulva was added and the liquid boiled for a few minutes. A slight infusion of seaweed in the artificial sea-water was thus made. The piece of Ulva was removed and the liquid allowed to cool. It was found that good cultures of the diatom could then be made in the solution. The slight infusion of vegetable matter therefore performed the same function as the 1 per cent of natural sea-water, which had been added in the previous successful experiments.

When, on the other hand, instead of making an infusion of the seaveed 
as a whole, a piece of the seaweed was burnt and the resulting ash added to the artificial solution, the diatoms did not grow.

These two experiments together make it probable, though they do not completely prove the point, that it is an organic extract of the seaweed, and not some inorganic salt dissolved out of it, which has made the artificial solution a suitable medium for diatom growth.

In other experiments it was found that if instead of adding a small quantity of natural sea-water from the open sea, the same quantity of sea-water taken from the tanks of the Aquarium were added, the resulting diatom cultures were larger and more vigorous. The Aquarium water seems therefore to contain more of the substance whose nature we are trying to determine than the water from the open sea. Now in the Aquarium animal life is more concentrated than in the sea outside, and one chief difference between Aquarium water and that brought in from outside is that the former contains more of the waste products of animal life. The suggestion here again is that the substance we are seeking is an organic substance, a substance produced by some living organism--in this case a waste product of the living fish.

It must, however, be one of the more stable organic substances, for it was found that if some of the Aquarium water was evaporated to dryness and the remaining salt heated to a comparatively low temperature, say, to $200^{\circ} \mathrm{C}$, and then again dissolved in distilled water, the solution thus obtained was practically as effective as natural sea-water in promoting diatom growth. The effective substance therefore can be dried and heated to at least $200^{\circ} \mathrm{C}$. without being destroyed. When, however, the heating was carried further, until a dull red glow was produced, the substance was destroyed or so altered that it ceased to stimulate growth.

Again we have the suggestion that the growth stimulant is probably an organic substance rather than a mineral salt. Further than this it has not up to the present been possible to carry the matter. In addition to small quantites of many inorganic salts, traces of a number of organic substances have been tried, amongst them being asparagin, calcium succinate, calcium malate, theobromine, tyrosine, urea and uric acid, but in all cases the results were negative.

An observation recorded by my colleague Mr. L. R. Crawshay is of much interest in commection with this point. Mr. Crawshay was carrying out experiments in which he tried to keep alive in the Laboratory some Copepods belonging to the species Calanus finmarchicus, which he was feeding on the diatom Nitzschia. He found that in the vessels containing the animals the diatoms grew and multiplied rapidly. If, however, the diatoms were put into similar vessels in which no animals were pre- 
sent, and kept under precisely the same conditions, very much less growth took place. Here again it looks as if some substance excreted by the animals helped to produce a luxuriant growth of the plants. The analogy seems complete with what we are all familiar with on land, the beneficial effect of animal manure upon plant life. A particular interest, however, attaches to Crawshay's work, because he did not get the increased diatom growth with other species of Copepods which he tried, but only with Calanus finmarchicus.

The outstanding feature then of the experiments which I have been describing to you on the growth of marine plankton diatoms, is the essential importance for the vigorous growth of these plants of some specific substance which is present in exceedingly minute quantities in natural sea-water and without which energetic growth does not take place. This substance, which acts as a growth stimulant, is, we have reason to suspect, a somewhat stable organic compound produced by other living organisms.

And now perhaps you will pardon me if I appear to wander into subjects which may seem far removed from my immediate purpose, but I hope I may succeed in showing how intimately the most diverse branches of scientific enquiry are often interwoven one with the other, and what unexpected light may be thrown upon a problem by investigations which at first sight look very remote.

Much striking work has been done recently on the subject of animal nutrition. At Cambridge Dr. Hopkins has shown that young rats do not grow when fed on an artificial diet composed of pure protein, starch, cane sugar, lard and inorganic salts, although such a diet, which we might almost call an artificial milk, contains all the generally recognised constituents of a perfect food. If, however, quite a small quantity of natural milk is added to this artificial food the young rats thrive. A minute trace of some substance present in the natural milk makes all the difference between growth and no growth.

Amongst the natives in some parts of Eastern Asia a very troublesome disease known as beri-beri has been prevalent in recent years, and has caused considerable mortality. It has been shown that the disease is directly caused by a too exclusive diet of polished rice. In the process of polishing, the outer husk or skin of the rice is entirely removed, and with the removal of the husk some substance is taken away which is essential if the rice is to be a sufficient food. The disease is at once cured by putting the patients on a suitable mixed diet.

The disease is also produced in pigeons if they are fed entirely on polished rice, and some interesting results on the cure of birds suffering from it have been obtained by Drs. Cooper and Casmir Funk. These 
investigators were able to extract from rice polishings a definite chemical substance, an organic compound of a highly complex character, which when added in exceedingly minute quantities to the diet of polished rice very rapidly cured the birds of the disease. To this substance, which is present in minute quantites in the husk of the rice, they gave the name of vitamine. They were able to isolate the same curative substance or vitamine from yeast, from milk and from bran. Another instance of a similar character concerns us more nearly in this country. In the preparation of fine white flour, from which our ordinary white bread is made, the outer layers of the wheat are entirely removed. It appears, however, that in these outer layers there is an active principle which is of essential importance to the value of the wheat as food material. In experiments carried out by Dr. Leonard Hill it was found that young rats and mice would not live when fed exclusively on white flour and water, whilst those fed on wholemeal flour did much better. Pigeons fed on a diet consisting only of pure white bread all died, but if to the white bread was added an extract of bran and sharps, that is an extract of the outer husks of the grain, the pigeons lived quite healthily. Here again we have to do with minute traces of the so-called vitamines, which are essential to healthy nutrition. In an ordinary mixed diet, such as is usually adopted in this country, the use of white bread made from refined flour is probably not very harmfu, as the small quantity of vitamine required will be obtained from other constituents of the food, such as milk or fresh vegetables. Amongst some of the poorer classes of the population, where white bread is often the principal food, there is a distinct danger of malnutrition, especially in growing children.

It seems probable that scurvy, a disease so dreaded by the deep-sea sailors of former days and one which has proved so disastrous to our Arctic and Antarctic explorers, is due to the absence from the diet of accessory substances similar in their nature to vitamines. These substances are present in minute quantities in lime juice, fresh vegetables and fruit, the addition of which to the diet has a curative effect on the disease.

1 comection between the study of the growth of marine diatoms and the study of the cause and cure of cancer may at first sight seem remote, but some recent work in connection with that disease certainly suggests that the two studies may be mutually helpful. In cancer we have a rapid and uncontrolled growth of certain tissues, and the work of H. C. Ross and others is directed to show that this rapid growth is due to the production in the body of the patient of minute quantities of certain complex organic substances, which act as growth stimulants and 
bring about the rapid and abnormal proliferation of the tissue cells. These growth stimulants have been termed auxetics, and it is not improbable that they resemble in their action, if not in their chemical constitution, the vitamines which cure the disease of beri-beri and the potent substance occurring in natural sea-water, the merest trace of which is capable of producing a luxuriant growth of diatoms in an artificial solution, which in its absence is unable to sustain growth at all.

- A still closer parallel to what occurs in the case of the diatom cultures has recently been brought to light in connection with agricultural research. I refer to the investigations of Prof. Bottomley, of King's College, London, on certain substances derived from Sphagnum peat. Sphagnum peat consists of the partly decayed remains of the Sphangum moss, which occurs so commonly in moorland bogs, as for example in much of the bogland of Dartmoor. Prof. Bottomley found that when Sphagnum peat was subjected to the action of certain bacteria obtained from soil, a kind of fermentation took place which resulted in the formation of a substance which, when fed to growing plants, stimulated and accelerated their growth to a quite surprising extent. This substance was soluble in water and was effective in very small quantities. Prof. Bottomley states that "Dr. Rosenheim, of King's College, found that seedlings of Primula malacoides potted up in loam, leaf-mould and sand, and treated twice with a water extract of only two-tenths ( 0.18 grams) of a gram of bacterised peat, were after six weeks' growth, double the size of similar untreated plants, and it was noted that flower production and root development were promoted equally with increase of foliage."

By using methods similar to those which had been employed in separating vitamine from rice polishings, Bottomley was able to separate the active substance from the bacterised peat and to test its effect upon the growth of wheat seedlings. Some seedlings were allowed to grow in a solution containing only pure food salts (nitrates, phosphates, and so on), whilst others were grown in the same solution to which one part in three millions of the active substance from bacterised peat had been added. During the first fortnight both sets of seedlings grew at about the same pace. After that those to which no active substance had been fed began to dwindle, and at the end of fifty days their weight had actually diminished by $8 \cdot 4$ per cent. Those seedlings, on the other hand, which had received the one part in three millions of active substance from the bacterised peat, continued to grow and at the end of the fifty days their weight had increased by 55 per cent of the original weight..

Bottomley's observations are of great practical interest, since they seem to explain in an intelligible way the beneficial effect upon crops of farmyard and organic manures. It is not sufficient to add to the soil 
only artificial fertilizers, since without a supply of the necessary accessory organic substances, which act as growth stimulants, the crops are unable to make use of the food supply which these artificial fertilizers provide. The accessory substances are, however, produced in the minute quantities. required when a certain proportion of organic manure is also employed.

But it is time for me to return to the conditions which prevail in the sea, although I hope that these digressions into animal nutrition, into the causes and cure of certain diseases, and into the treatment of agricultural crops have been of some service in throwing light upon the subject in hand. What is the source from which the sea obtains the food substances necessary for the growth of its plant life-the phosphates, nitrates and other inorganic salts and the organic substances of the nature of growth stimulants? There is clearly within the sea itself a continuous cycle of these plant foods, and we may to that extent regard the sea as a selfcontained whole. The plant makes use of the food substances dissolved in the water and is then itself eaten by some animal. The animal, either directly as the product of its own vital activity or indirectly through the action of putrefying bacteria when it dies, returns the plant foods to the sea.

In addition, however, to this food cycle within the sea itself, there is another source of supply, the importance of which is probably very great, though up to the present it has not been studied with all the attention it deserves. This source of supply is the material carried into the sea by drainage from the land, the great bulk of it being, of course, brought down by the rivers. The subject has recently been discussed in an important memoir by Prof. Gran of Christiania. It has long been known that life in the sea is specially abundant in the neighbourhood of the coasts and in regions which are under the influence of currents containing a great admixture of river water. The study of the distribution of the plankton, or floating life of the sea, has helped greatly in throwing light upon this question. The quantity of plankton in coastal waters is very much greater than that found in the open ocean far from land. The proportion has been estimated at 50:1.

Prof. Gran maintains that this can only be explained by supposing that the coastal waters are richer in nutritive or food substances, and these nutritive substances must have been supplied by drainage from the land. It has been found that the development of the plankton, especially of the plant plankton, commences in the inshore or coastal waters and from thence spreads out gradually into the ocean. All the great fishing areas are found in regions where coastal water predominates and where the admixture of river water is large. The North Sea, the most productive 
area of the British fisheries, receives the waters of the Rhine, the Elbe, the Thames, and many other rivers. The great cod fisheries off the coast of Norway take place in waters. which are derived in large part from the Baltic current. The Bristol Channel and Irish Sea are other examples upon a smaller scale.

On the other hand, over the vast areas of the open ocean far from the coasts, where the influence of land drainage is not felt and where the quantity of minute life in the water is small, no important fisheries are carried on. As far as we seem to understand the conditions of the problem at present, it does not appear likely that any great fisheries can be developed in these open waters. Just as the desert areas of the land, notwithstanding the abundant energy of sunlight which falls upon them, are umable to support vegetation from lack of water, so it seems these great ocean wastes fail in making use of the sun's power for the production of organic life from lack of substances which only the land can supply. If this be a true view of the case, when, as will probably happen sooner or later, the fisheries of the coastal banks have reached the maximum extent of their capacity, we shall have to look for any further increase of the supply of fish for food purposes to an extended practice of fish culture, a method at present confined almost entirely to fresh-water fishes. The extension of fish culture to marine fishes, which are much more delicate and difficult to rear than those which live in fresh-water, is by no means an easy matter, and much further knowledge will be necessary before successful results can be obtained. The researches which I have described to you to-night were commenced largely with a view to obtaining information about some of the fundamental problems upon which any scientific practice of fish culture would need to be based. The investigation has at the present time reached only an early stage, but the results obtained are unexpected and not without interest. There seems reason to hope that a further extension of the work may be of some practical importance.

For a more detailed account of the researches referred to in this address see :-

Alden, E. J., and Netson, E. W., On the Artificial Culture of Marine Plankton Organisms, Quart. Journ. Micr. Sci., Vol. 55, p. 361, 1910, and Journ. Mar. Biol. Assoc., VIII, p. 421, 1910.

Aluen, E. J., On the Culture of the Plankton Diatom Thalassiosira gravida Clece, in Artificial Sea-water, Journ. Mar. Biol. Assoc., X, p. 417, 1914. 